\title{
CORRELATION OF GLYCOSYLATED HEMOGLOBIN AND BMI IN TYPE 2 DIABETES MELLITUS PATIENTS
}

\author{
Narasimha Rai $K^{1}$ \\ ${ }_{1}^{1}$ Professor and HOD, Department of Physiology, Chamarajanagar Institute of Medical Sciences, Chamarajanagar, Karnataka.
}

ABSTRACT: BACKGROUND: The risk of diabetes increases progressively with increasing body mass index and waist-hip ratio. Obesity is a positive risk factor in the development of type 2 Diabetes mellitus, dyslipidemia, insulin resistance and hypertension. AIM :The present study was undertaken to correlate glycosylated hemoglobin and BMI in type 2 Diabetes mellitus patients.

MATERIALS AND METHOD:The study includes 101 type 2 diabetic patients and were divided into Group 1 with 47 Diabetic patients with BMI $<25$ and Group 2 with 54 Diabetic patients with BMI $>25$. Glycosylated hemoglobin was measured by auto analyzer method. Any value $>7 \%$ were considered as increased HbA1c. HbA1c was measured after one month of recording FBS \& PPBS levels. BMI was calculated by dividing weight in kilograms by the square of the height in meters $(\mathrm{Kg} / \mathrm{m} 2)$.

STATISTICAL ANALYSIS was done using one-way ANOVA and $\mathrm{p}<0.05$ was considered as significant.

RESULTS: From our study, we found that the glycosylated hemoglobin levels were higher in diabetes mellitus patients with BMI > 25 , and it was statistically significant.

CONCLUSION: The mean $\mathrm{HbA}_{1 c}$ levels were higher in individuals in the diabetic group with BMI > 25 .

KEYWORDS: Type 2 Diabetes Mellitus, Glycosylated Hemoglobin.

HOW TO CITE THIS ARTICLE: Narasimha Rai K. "Correlation of Glycosylated Hemoglobin and BMI in Type 2 Diabetes Mellitus Patients". Journal of Evolution of Medical and Dental Sciences 2015; Vol. 4, Issue 92, November 16; Page: 15739-15740, DOI: $10.14260 /$ jemds/2015/2272.

INTRODUCTION: Obesity is an abnormal growth of the adipose tissue due to an enlargement of fat cell (Hypertrophic obesity) or an increase in fat cell number (Hyperplastic obesity), or a combination of both. Obesity is a major risk factor for type 2 diabetes mellitus. Obesity is often expressed in terms of body mass index (BMI).[1]

The estimation of urine and blood sugar levels are done commonly for diagnosis and monitoring of glycemic control, and they are subjected to various physiological and pathological fluctuations.

They represent the current glycemic status of the patient and they are poor indicators of long-term control of diabetes. For the last few years, estimation of glycosylated hemoglobin and fructosamine has been increasingly used to achieve better monitoring of long-term glycemic control in diabetics.

When plasma glucose is consistently elevated, there is an increase in non-enzymatic glycation of hemoglobin. This alteration reflects the glycemic history over the previous 2 to 3 months, since erythrocytes have an average life span of 120 days.[2]

Formation of glycated hemoglobin is irreversible, and the blood level depends on both the life span of the red blood cell (Average 120 days) and the blood glucose concentration.

Financial or Other, Competing Interest: None.

Submission 16-09-2015, Peer Review 18-09-2015,

Acceptance 05-11-2015, Published 13-11-2015.

Corresponding Author:

Dr. Narasimha Rai K,

Department of Physiology,

Chamarajanagar Institute of Medical Sciences.

Chamarajanagar, Karnataka, India.

E-mail: raisimha24@rediffmail.com

DOI:10.14260/jemds/2015/2272.
The amount of HbA1c therefore represents the integrated values for glucose over the preceding 6 to 8 weeks and provides an additional criterion for assessing glucose control. Values are free of day-to-day glucose fluctuations and unaffected by exercise or recent food ingestion. The interpretation of glycated hemoglobin depends on the red blood cells having a normal life span. Patients with hemolytic disease or other conditions with shortened red blood cell survival exhibit a significant reduction in $\mathrm{HbA1c}$. High $\mathrm{HbA1c}$ levels have been reported in iron deficiency anemia, probably because of the high proportion of old erythrocytes.[3]

AIM AND OBJECTIVE: The present study was undertaken to correlate glycosylated hemoglobin and BMI in Type 2 Diabetes Mellitus patients.

MATERIALS AND METHODS: The present work was carried out at KMC hospital, Attavar, Mangalore, after a written consent from all the participants and the institutional ethical clearance. The study includes 101 diabetic patients and were divided into Group 1 with 47 Diabetic patients with $\mathrm{BMI}<25$ and Group 2 with 54 Diabetic patients with BMI>25.

A detailed history was taken. General physical examination including height, body weight, blood pressure, pulse rate, respiratory rate and complete systemic examination was done. Fasting blood sugar (FBS), postprandial blood sugar (PPBS) and glycosylated hemoglobin (HbA1c) were studied. Drug history was taken. The patients diagnosed for Type 2 diabetes were included in the study whereas; patients with Type 1 diabetes were excluded in the present study.

Major selection criteria for diabetes included: a random plasma glucose level of $200 \mathrm{mg} / \mathrm{dL}$ or greater when the 
symptoms of diabetes were present and a fasting plasma glucose level of $126 \mathrm{mg} / \mathrm{dL}$ or greater.

STATISTICAL ANALYSIS: Data are expressed as Mean \pm SEM. Statistical analysis was done by using "ANOVA"; students ' $\mathrm{t}$ ' test. Tukey's test was used in intercomparison of the three groups. $\mathrm{P}$ value was taken as significant at 5 percent confidence level $(\mathrm{P}<0.05)$.

RESULTS: There were 47 individuals in the diabetic group with $\mathrm{BMI}<25$, and their mean $\mathrm{HbA}_{1 c}$ level was $7.71 \%$, and 54 individuals with $\mathrm{BMI}>25$, and their mean $\mathrm{HbA}_{1 \mathrm{c}}$ level was 8.65\%. The mean $\mathrm{HbA}_{1 \mathrm{c}}$ levels were higher in individuals in the diabetic group with BMI $>25$. (Table-1, Fig-1).

\begin{tabular}{|c|c|c|c|}
\hline & $\begin{array}{c}\text { BMI < 25 } \\
(\mathbf{N = 4 7 )}\end{array}$ & $\begin{array}{c}\text { BMI > 25 } \\
(\mathbf{N = 5 4 )}\end{array}$ & P value \\
\hline HbA $_{1 \mathrm{c}}(\%)$ & $7.71 \pm 0.14$ & $8.65 \pm 0.07$ & $0.001^{* * *}$ \\
\hline
\end{tabular}

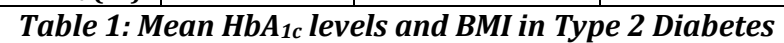
Mellitus. Data were expressed as Mean \pm SEM.

*** Highly Significant

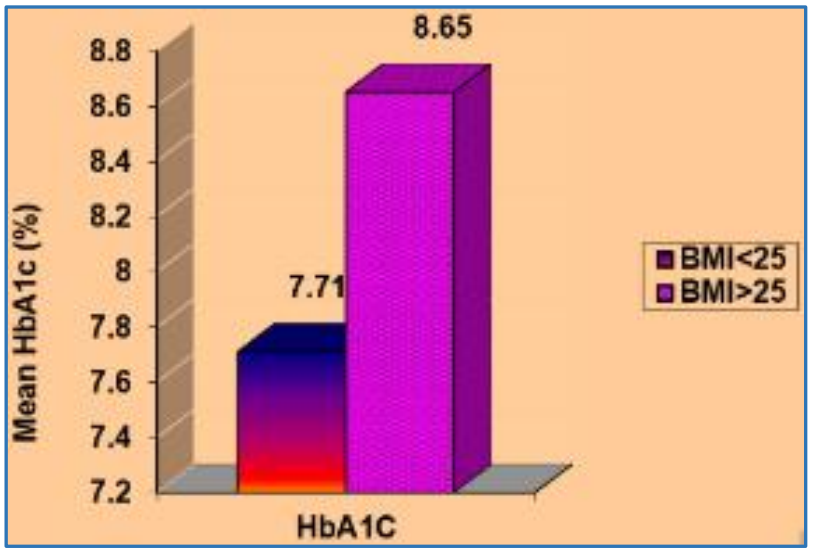

Fig.1: Mean HbA1c (\%), \& BMI in Diabetic group

DISCUSSION: Risk of type 2 diabetes increased progressively and significantly with increasing levels of initial BMI, and also with the duration of overweight and obesity. Studies have shown the critical importance of overweight and obesity, particularly of long duration, in the development of type 2 diabetes and support the current public health recommendations to reduce the risk of type 2 diabetes by preventing weight gain in middle-aged men who are not overweight, and by encouraging weight loss in overweight and obese men. ${ }^{[4,5]}$

In normoglycemic subjects, a small proportion of $\mathrm{HbA}$ is attached to carbohydrate moiety, and forms glycosylated hemoglobin. In conditions of sustained hyperglycemia, such as diabetes mellitus, the proportion of hemoglobin that is glycosylated is increased substantially. This glycosylation is the result of post-translational modification of $\mathrm{HbA}$ molecules. The binding of glucose is a non-enzymatic process that occurs continuously during the life of the red blood cell. Thus the amount of glycosylated hemoglobin reflects the glycemic control of a patient during the 6-8 week period before the blood sample was obtained.[6]

CONCLUSION: In our study the mean $\mathrm{HbA}_{1 \mathrm{c}}$ levels were higher in individuals in the diabetic group with BMI $>25$.

\section{BIBLIOGRAPHY:}

1. Park K. Obesity. In: Park's textbook of Preventive and Social Medicine. 18 $8^{\text {th }}$ ed. M/S Banarsidas Bhanot: Jabalpur (India): 2005; 316-319.

2. Powers AC. Diabetes Mellitus. In: Kasper DL (ed). Harrison's Principles of Internal medicine. $16^{\text {th }}$ ed. Mc Graw-Hill companies. Inc.2005; Vol II: 2152-2180.

3. Sacks DB. Glycated hemoglobin. In: Burtis CA, Ashwood ER(ed). Tietz text book of clinical chemistry. $2^{\text {nd }}$ ed. W B Saunders Company, Philadelphia. 1994: 980-86.

4. Raben A, Anderson HB, Christenson NJ, Madsen J, Holst JJ. Evidence for an abnormal postprandial response to a high fat meal in women predisposed to obesity. Am J Physiol. 1994; 267: E549-E559.

5. Wannamethu SG, Shaper AG. Weight Change and duration of overweight and obesity in the incidence of type 2 diabetes. Diabetes care. 1999; 22 (8): 1266-72.

6. Bennett PH. Diabetes-Definition and Pathogenesis. In: Kahn CR, weir GC (ed). Joslin's Diabetes Mellitus. 13 ${ }^{\text {th }}$ ed. Lea and Febiger, 1994; 193-200. 